\title{
Amateurism and professionalism in work and learning
}

\begin{abstract}
This article explores the concept of amateurism as a form of critique and addition to the concepts of professionalism, professional work and education. While amateurism is usually conceived pejoratively, the notion of doing something 'for the love of it', even if one is not formally qualified, opens up the possibilities for conceiving new forms of work, worker and sets of working relationships based upon different conceptions of expertise. Drawing upon historical and contemporary studies of the contribution of amateurism to professional work, and exploring the role of digital technologies in enabling amateurs to contribute to forms of professional practice, the article explores some of the challenges posed for work and learning, and suggests some lines of research to be explored.
\end{abstract}




\section{Amateurism and professionalism in work and learning}

\section{Introduction}

The amateur is usually positioned as in some ways a lesser contribution than the professional to workplace practices due, in part, to their lack of formal educational qualifications in the relevant area. Indeed amateurism in the workplace might well be viewed as highly detrimental given contemporary concerns for productivity, quality and excellence. In many areas, such as surgery, there is an obvious preference for the professional surgeon rather than the amateur, although circumstances might not always allow for a professional to be available to perform the task e.g. injury in war. The normative claims to the professionalising of practice through learning and qualifications to ensure quality and consistency seem unassailable, even if the empirical evidence is less so, as evidenced by the many reports of the failures of professionalism in workplace practices.

In relation to the public service, in particular, the normative claims for professionalisation are often seen to be necessary and integral to the enhancement of provision. Public services can be defined as those organisations 'contracted to provide services to the public on behalf of Government' (Oxford Economics, 2008, p.1). In recent years, there has been much debate about the roles of para-professionals, volunteers and users in the provision of such services. In the UK context, health, social care and education have all witnessed changes which have, at one level, enhanced and entrenched professionalisation e.g. nursing has become a degree level profession. However, others, such as family carers, teaching assistants and volunteers of various kinds have been introduced into or given higher status in relation to service delivery in a range of areas. This has not been without contention. 
However, what is noticeable in such moves and debates is the relative lack of interest in or reference to amateurs and amateurism and the possible contributions they can, could, or do make to public services or professional work more generally. Conceptually and politically the amateur is silenced, despite being the key antonym for professional, while volunteers, lay people and users now have established, if contested, status. The fact that concepts other than amateur are deployed no doubt reflects the negative connotations it carries. How this has evolved is part of the focus for this article. More broadly, it is to an exploration of the possibilities for drawing upon a conception of the amateur in debates about the provision of professional public services and some its implications for learning and work that this article is addressed. I shall explore the historical background to the emergence of professionalism and examine studies that have explored the exclusions from and roles of amateurism in certain work practices. I shall then lay out a possible research agenda for examining the possible roles of amateurs in work. To be clear at the outset, I am not arguing for the demise of professional practice in workplaces, nor the education and qualifications associated with professionalism. However, I am interested in how the concept of the amateur might be rehabilitated to contribute to the provision of goods and services alongside professionals and others as part of workplaces and some of the educational issues with which this may be associated. I am also interested in whether aspects of amateurism, in particular, doing things 'for the love of it', might normatively open up new possibilities for what we have come to think of as professional practices.

The context for this is the modernisation and reform of public services which has been a continuing contemporary policy refrain within the European Union, particularly in the provision of education, health and social care. They are critical to addressing the social, economic and political challenges facing the Union, national responses to which are varied. 
Factors such as increasing societal expectations, complexity of social problems, costs and cuts in public services, particularly in the wake of the financial crisis in Europe, and the potential of new technologies have underpinned demands for reform. One central aspect of the reform agenda in Europe has been an increasing emphasis on services becoming more responsive to users, families and community members. These take many organisational forms linked to notions of, for instance, market responsiveness, co-production, transparency and open access to information. A second key aspect of reforms has placed an emphasis on the personalisation of public services and the need for professionals to work more effectively in integrated multi-professional teams. In some areas of public service practice for instance, clients have become positioned as experts of their own experience (e.g. Novotny, 2000), raising fundamental questions about the notions of knowledge, experts and experience (e.g. Nowotny et al., 2001; Collins and Evans, 2007) and how professionals are positioned in relation to what they do and what they know. This has produced significant new challenges to traditional roles and practices for all those involved, raising issues of boundaries, expertise, qualifications and identities (Fenwick, 2012a, 2013).

Research and policy have, to date, focused primarily on the reforms to the relationship between service users and providers and the implications for professionals, professionalism and professional education. Enhanced qualifications and continuing professional development have become mantras for the enhancement of service delivery and ensuring that professionals maintain their competence and expertise. What has been given less attention has been the nature and status of those providing the services, in particular, the extent to which the latter are provided by the professionally qualified alone. This article examines the issue from a new and alternative angle by focussing on a gap in the research and policy debates regarding the actual and possible role of amateurs and amateurism - which I define 
as those without the formal qualifications or professional accreditation - in public service delivery specifically and professional work more generally. This puts to one side the normative assumption that public services are best provided by professionals alone. It also requires me to comment on conceptual and empirical differences between amateurs and volunteers in the existing literature.

The article is in three parts. First, I outline some of the views around notions of professionalism and amateurism and the ways in which the qualities of each are often collapsed into particular roles in the labour market. This opens up the questions of whether all professionals demonstrate the qualities of professionalism ascribed to them and, similarly with amateurs. Similar or complimentary qualities, knowledge and expertise may reside in different roles. There is also the normative question of what qualities and knowledge should reside in particular roles. Here I will question any easy binary between professionalism/good and amateurism/bad. Second, I shall explore existing research into the ways in which historically and in the contemporary world professionals and amateurs work together and how that has evolved. This points to the many areas and many ways in which professionals and amateurs have and do work together in work practices, although to date there is limited research into education and learning in such contexts (for an example, see Raddick et al., 2013). I shall outline also issues associated with sources of information and authority upon which amateurs and professionals draw and, in particular, the increasingly important mediating influence of technologies and the learning associated with them. In conclusion, I shall argue for the possibility for a reframing of research into professional work that embraces rather than silences the amateur. As I have indicated, I am writing largely in the context of Europe, but I hope this conceptually led article can be part of a wider geographical set of dialogues on professional work and learning. 


\section{Professional-s/ism and Amateur-s/ism}

Over the last century we have seen increasing trends towards the professionalisation of expertise in society in many parts of the globe, alongside the development of modern public institutions and the growth of higher education. An ever widening range of working activity is now positioned as 'professional' and, with that, there has been increased institutionalisation, standardisation, qualification and regulation of practice (Friedson, 1988). In many areas, particularly in the public sector, professionalisation has been increasingly associated with elite qualifications, status, and service to society (Evetts, 2011). Many occupational groups, such as nurses and teachers, have sought and gained professional status through increased qualification and the development and adherence to professional codes of practice.

These processes are not linear, and they take different spatio-temporal forms and trajectories around the globe. In the UK, the process of professionalisation associated with elite qualifications, standardisation and regulation of practice has gone on throughout the $20^{\text {th }}$ century. These processes of professionalisation have not been without criticism. In particular, it has been argued that professionalism represents restrictive practice within the labour market and is a form of producer capture. In other words, restriction on entry to the profession through control of numbers of entrants to relevant university programmes provides the basis for maintaining pay, conditions and status. It is suggested that this means that services start to become run in the vested interests of the professionals more than for the users of those services (Johnson, 1972). From across the political spectrum professionals have been criticised for paternalism and elitism. Here professional status is an occupational strategy to protect and enhance pay and conditions. 
This is an argument put forward in relation to the early development of professionalism in the UK. In his study of the work practices of Biology and Natural History in late Victorian Yorkshire, Alberti (2001) argues that professionalism was an occupational strategy of a particular kind of elite who contrasted themselves with others, including amateurs. Part of the way in which this was done was by the institutionalisation of certain knowledge and practices as 'subjects' within the university curriculum, the teachers and researchers of which garnered professional status, by contrast with those working outside the university. In more recent times, the introduction of market mechanisms and attempts to develop the co-production of services with users (Bovaird, 2007; Fenwick, 2012b) have both been utilised as ways of addressing these concerns about paternalism and producer capture as part of the reforms of professional practice.

However, despite such critiques and reforms, there persists a tendency in society to accept professionalisation normatively as an unconditional good to be pursued by occupational groups (Evetts, 2009). This is where we need to distinguish professional status and professionalism as a set of practices and values. Professionalism is commonly taken to be a mark of commitment, vocation and service to the community. If these are normatively taken to be good things, then certain types of reform, such as those associated with market, audit and accountability agendas tend to be positioned as resulting in forms of deprofessionalisation and therefore negative. Thus, much of the existing research on reforms and changing practices in the public services over an extended period has tended to focus negatively on issues of de-professionalisation and re-professionalisation linked to neo-liberal economic policies, new forms of governance and new public management approaches to the organisation of work (for example, Week, 1998; Seddon, 1997; Clarke, 2005). 
Here the modernisation of public services is taken to be an ideological construct behind which lies an attack on professional groups and professionalism, where these are seen as mutually bound together. The use of para-professionals, volunteers and users in the delivery of public services is here part of a strategy to undermine the pay and conditions of professionals to provide services 'on the cheap', that is, at less direct cost to the state, with an associated threat to quality of service. However, central to much of the academic debate is the extent of agency, autonomy and accountability in the practices of the professional groups concerned. Evetts (2011) argues that the notion of professional autonomy is itself misleading, however, as she identifies discretion rather than autonomy as integral to professional practice. Research on these issues has a long history and is well established.

By contrast, research on the amateur and amateurism, unlike volunteering, is less well covered. While national and local surveys and studies of volunteering are well established and the volunteer is generally viewed positively, to be attributed an amateur status would often be assumed to be pejorative. Amateurism is often associated with leisure rather than work pursuits, unpaid rather than paid and with a lack of expertise, quality, or qualifications (Stebbins, 1992). In many domains, amateurism has become a pejorative term when contrasted with professionalism, suggesting unprepared and unreliable practices at worse or less than optimum performance at best. A classic example here is the contrast between amateur and professional sports persons, where the performance of the latter is clearly higher than that of the former. It is also important not to ignore the contexts of amateurism, as, for instance, the amateur archaeologist in the UK was historically often a male member of leisured and monied classes. Further, feminists have long pointed to the critical role that women play in relation to unpaid work, specifically in the caring services and in home-based 
care, and the exploitation that is associated with this (Waring, 1988). In other words, professionalisation in some domains might be argued to be part of a reordering of the social to enable greater security, recognition and mobility within the labour force. To be an amateur may rely on already having an income from elsewhere.

But what of amateurism as a set of qualities? While mostly viewed pejoratively, amateurism can also have more positive connotations. Here I believe it is possible to open up what has been a silenced aspect in the development of professional practices. Historically, the linguistic roots of the notion of amateurism lie in Latin and Old French notions of 'love' (amator). In this sense, amateurism can be associated with a sense of vocation and the idea of a vocational 'calling' towards engagement in certain practices, doing things 'for the love of it' rather than for pay and status. Doing things for the love of it can also be associated with the notion of volunteering wherein 'public service motivation' has been increasingly established as a valid way of identifying morally committed citizens (Perry et al., 2008).

In a recent literature review conducted in the UK, Ellis et al. (2010) identified volunteering as a useful term, despite concerns in the field that the stereotype of the volunteer - older, more affluent, more educated, and white - might put others off from contributing to voluntary activities. Surveys in the UK tend to show that the stereotype is a reasonably accurate description of the bulk of volunteers. Having discussed previous attempts to define volunteering, Ellis et al. (2010) focus on three characteristics: it is unpaid, undertaken by free will and is of benefit to others. We see how volunteerism overlaps with amateurism, but conceptually is silent on questions of expertise and qualifications and differs on motivation. To benefit others may relate to doing something for the love of it, but is not the same. 
While qualifications are seen as integral to professionalism, the sense of calling and doing things for the love of it associated with amateurism is also something that is claimed by some professionals and as an aspect of their working practices. Professional service to the community can be seen as an expression of vocation, of love. Yet professionals are qualified and paid, while amateurs are not. It might also be argued that while amateurs and professionals may share certain qualities, professionals work to and are expected to work to higher standards than amateurs. Amateurs are not expected to have the same degree of knowledge and expertise as professionals. Thus part of the occupational strategy of professionalisation might entail the adoption of certain positive qualities of amateurism by professionals as things to be valued and paid for, and the attribution of only less positive qualities to amateurs and amateurism. With professionals one expects to get qualities, expertise and standards of practice and that is worth paying for. But are aspects of amateurism in the heart of professionalism, even as professional groups seek to clearly distinguish themselves from amateurs? If this is the case, then might we not look at the role of amateurism and amateurs in contributing to professional work more positively? Can amateurs possibly achieve and maintain professional standards without being formally qualified? Do professionals need to be qualified in order to be effective in the workplace? Does the development of professional expertise require formal education in part or at all? These are questions already pursued in relation to questions of formal expertise and experiential learning (e.g. Collins and Evans, 2007), but not linked to questions of amateurism.

Amateur contributions can take many forms, such as well-trained first aiders, voluntary firefighters, amateur astronomers and photographers, and citizen scientists and journalists (e.g. Allan and Thorsen, 2009; Roy et al., 2012; Raddick et al., 2013). Arising from this re- 
evaluation of amateurism and the possible contribution of amateurs, in the UK, we have witnessed therefore arguments for the greater role of amateurs in public service delivery alongside professionals (Leadbetter and Miller, 2004). However, despite this, existing research on amateur-professional relations remains largely focused in areas other than the public services and amateur contributions to such services are overwhelming framed in terms of the concept of volunteering.

I have attempted to make a case for considering amateurism more seriously and its potential contribution and that of amateurs in the delivery of public services in particular and work more generally. There are a range of conceptual tangles this raises, both in relation to professionalism and voluntary work, and their implications for professional education and the requirement for qualification. I now turn to some of the historical and empirical evidence on the roles of amateurs in work practices to give some evidence to support the conceptual argument.

\section{Amateur-Professional Relations in Workplaces}

As I have indicated, the attempts to define professionalism have been varied, but many analysts continue to invoke classical characteristics, such as self-regulation, specialist knowledge and qualifications, codes of practice, systems of licensing, etc. (Friedson, 2001). These characteristics reflect historical and national contexts within which the category of 'professional' has developed and the outcomes of on-going struggles to exclude certain practices and practitioners as non-professional or amateur. For instance, Alberti (2001) argues that the rift between amateurism and professionalism in science in the UK is a fallacy consciously shaped by an opposition to a particular pejorative notion of the amateur by laboratory-based sciences as part of a professionalising occupational strategy. Here there 
emerged a mapping of the notion of professional practice onto laboratory work and amateur practice onto field and non-expert work. Employment by the university became the mark of the professional scientist. This was reinforced by the institutionalisation of certain (expensive) technologies and practices within the university that were necessary to undertake expert work and which acted as further markers of professionalism. This example is consistent with some arguments about professionalism as a form of producer capture.

Similarly, in his study of the emergence of Astronomy as a university subject in the late nineteenth century and the growth of the professional astronomer, Lankford (1981) pointed to the important role of 'semi-amateurs'. He also showed the parting of the ways between professionals and amateurs in this area, as the former began to differentiate themselves through specialised knowledge gained by advanced study and access to research facilities supported by government funding. As the subject developed with increased reliance on expensive instrumentation, so the division between the professional and amateur became more deeply inscribed. In relation to astronomy, where the contribution of amateurs to professional work is much in evidence in, for instance, citizen science projects such as Galaxy Zoo (Raddick et al., 2013), Boltwood (2000) suggests that amateurs need to consider the particular contribution they can make to the subject. He argues that they need not compete with professionals in relation to the generation of higher quality data and theoretical sophistication, but supplement professional work and make distinctive contributions. Star and Greisemer's (1989) seminal study of the work of amateurs and professionals in a museum of zoology in the early twentieth century is a further case in point. They and others following them have pointed to the relational ways that roles are specified between amateurs and professionals to support work practices. 
Thus, in certain fields, research indicates that the role of the amateur has been more critical historically to the emergence of professions and professionalism and to innovation within a wide variety of practices than many of us would probably expect. In particular and as evidenced, there has been much research on the role of the amateur in the history, development and professionalisation of the sciences. Amateurs continue to play a significant role in a range of scientific endeavours, such as astronomy and open source software development, often now under the banner of citizen science (Roy et al., 2012), where the concepts of citizen, volunteer and amateur are used interchangeably and in unproblematised ways. There are two inter-related aspects to the role of the amateur in relation to professional practice these examples bring up. First, there is the notion of the amateur who works to the equivalent of professional standards. Second, there is the role that the amateur can play alongside the professional. Each raises questions about how those amateurs develop their particular qualities and expertise to be able to contribute and what they learn from contributing to professional work.

Relationships between amateurs and professionals are not something of sole relevance to the development of the professional sciences. In areas such as music, history, software development, photography, design, journalism and sport, the amateur as volunteer has historically made important contributions, and debates about the relative status of the professional and amateur in terms of expertise and ethos continue to this day. Thus, in relation to design work, Beegan and Atkinson (2008) suggest that the availability of less expensive technologies, rather than excluding amateurs, has enabled them to play a range of roles. Amateurs do not emulate professionals. This serves as critiques of professional practice, to which professional designers respond in an oscillation between fear and admiration. Such studies point to the ways in which relations between amateurs and 
professionals change over time and context, and that these can be productive if troubling for those involved.

In some areas in the last decade, there has been the emergence of an argument for what Leadbeater and Miller (2004) refer to as the 'Pro-Am'. These are individuals who it is suggested are engaging in voluntary activities as amateurs, for the love of it, but working to professional standards. In other words, one does not need professional qualifications, pay and status to work professionally to the necessary standards in certain areas of work. It is argued therefore that Pro-Ams have many of the defining features of professionals, including a strong sense of vocation, the use of professional standards to assess performance, and the forming of self-regulating communities producing non-commodity services and products. They are well versed in a relevant body of knowledge and skill and have a strong sense of tradition and identity.

For Leadbetter and Miller (2004), Pro-Ams sit within a spectrum of relationships between amateur and professional embracing notions of the 'committed amateur' and 'quasiprofessional'. Leadbetter and Miller further trouble the simple amateur-professional divide by pointing to the survey data illustrating the professional status in one domain of many people engaged in amateur voluntary work in another. They give a number of contemporary examples of Pro-Ams, for example, many contributing to the development of open source software. In their examples, Leadbeater and Miller (2004) point to the importance of new technology to the practices of amateurs. While this has resulted in a developing literature on e-professionalism (e.g. Cain and Romanelli, 2009; Greyson et al., 2010; Mansfield et al., 2011), less attention has been given to the sources and uses of information and influence by amateurs. However, Leadbetter and Miller point out how in astronomy new discoveries are 
being made based upon the increased availability of low cost, high quality telescopes. Beegan and Atkinson (2008) make similar claims for changes within the professional practices of design. In particular, they refer to a form of amateur design practice based upon 'dilettantism', where the latter is usually used pejoratively. They suggest that the lack of professional attachments can enable amateurs to 'dabble, combine and cross disciplines' (Beegan and Atkinson, 2008, p.309) in ways which encourage hybridity, creativity and innovation. In other words, amateurs can sometimes be more innovative than professionals in what they do, precisely because they are not subject to the certain standards and accountabilities of those groups. Their study points to some of the different design practices engaged in by amateurs and how these can act as models for revised professional practice.

Another important contemporary example of amateurs contributing to professional practice through the use of new technology is that of citizen journalists (Allan and Thorsen, 2009; Czarniawska, 2011). These amateurs post items on the internet and make extensive use of social media, thereby both creating and contributing to news stories around the globe, which can then be drawn upon and mediated by professional journalists. Obviously while these may not be paid professional journalists, some might not be distributing stories or images for the love of it, but for other purposes, such as politics. However, despite criticisms, the role of widely available technologies would appear to be important to new possibilities for amateurs and professionals working together. Indeed crowdsourcing technologies (Estellés Arolas and González Ladrón-de-Guevara, 2012; Raddick et al., 2013) are now playing an explicit role in linking amateurs and professionals for both unpaid and paid work and there is increasing acceptance of both its effectiveness and the possibilities it raises for learning among contributors to work and projects (Dodge and Kitchin, 2012). 
Leadbeater and Miller (2004) position Pro-Ams as part of a broader trend away from hierarchical models of work with professionals at the top towards more distributed and innovative organisational models. They also suggest that professionals have strengths in formal theory whereas Pro-Ams are more versed in know-how. However, the empirical basis for such claims and their generalisability across different work and national contexts is very limited. There are also significant questions regarding the nature and authority of the knowledge, skills and qualities brought to situations by amateurs and professionals, their sources of influence and information (Klette and Smeby, 2012), the learning that both groups experience through contributing to workplace practices and the forms of accountability to which they can be subject.

While Leadbeater and Miller are positive about the role of amateurs and Pro-Ams in work practices, others, such as Keen (2007), provide a more critical view, suggesting that 'the cult of the amateur', in particular on the internet, has a negative impact upon culture. In the realm of medicine, there has also been concern about patients self-diagnosing from internet sources and challenging professional diagnosis by doctors. Here distinctions, for instance, between high and popular culture, and formal and folk knowledge, certificated and uncertificated learning remain critical in demarcating the work of professionals and thus the authority that they can claim within and beyond their particular domains, which raises issues about the nature of expertise and responsibility. Whether such demarcations can or should be taken for granted is one of the questions raised by an interest in amateurism. Questions are also raised about the sources of information and advice that professionals and amateurs draw upon and learn from in developing their own practices and relationships with each other and associated issues of power, status and inequality. It also raises issues of accountability, such as where 
responsibility lies when things go wrong, and how standards of practice are to be regulated and enforced in different configurations of work.

\section{Research Agendas}

It is clear that conceptually and empirically the status and contribution of amateurism and the amateur to work and their relations with professionalism and professionals are multi-faceted, complex and contested, as is the role of amateurism is work per se. In his study, Meyer (2008) points to the spatialities - the spaces of and for participation - temporalities - the amount and quality of time to be given - and materialities - objects and tools - of amateur and professional participation in work. He argues that amateurism is not an essence, but is 'relationally defined through fragile connections and demarcations' ( $\mathrm{p} 49$, emphasis in original). The roles and relationships between amateurs and professionals, amateurism and professionalism are not fixed, but emerge from the constant possibilities and struggles to contribute to the specified domains of practice, within which questions of technology, specialist knowledge, qualifications, standards of practice, organisational structures, national and occupational context and status are central. They impact on the authority and accountability of those involved in work practices. However, while there has been increased focus on issues of multi-professional and inter-professional working in public services (e.g. Edwards et al., 2009), less attention has been given to the wider debates about the amateur and professional and their significance for professional education and workplace learning.

The argument above provides a basis for developing a research agenda in relation to public service reform in Europe and beyond, which focuses on:

- distinguishing the qualities of professionalism and amateurism from the status of professionals and amateurs 
- the relationships between amateurs and professional in public service delivery and work more generally;

- the sources of expertise and experience upon which they draw;

- the forms of workplace learning in which they participate;

- the issues of authority and accountability in the delivery of public services;

- the role of new technologies in enhancing possibilities for amateur contributions to professional work;

- the impact of different forms of national and occupational contexts and organisation upon those engaging with public services.

Conceptually, while drawing a contrast in this article between the antonyms of amateurism and professionalism, there is also the need to explore further the wider relationships with volunteering and citizen-based projects.

For those who associate professionalisation as normatively necessary to delivering high quality public services, such an agenda might appear threatening. However, it points to the need for those holding such a position to be able to justify it empirically. We cannot take professionalism for granted and some forms of amateurism may have things to offer workplaces that have yet to be fully developed. What forms of professional work can benefit from what forms of amateurism is something worthy of further research, as are the forms of learning and expertise of those involved.

\section{References}

Alberti, S. (2001), “Amateurs and professionals in one country: Biology and natural history in late Victorian Yorkshire", Journal of History of Biology, Vol. 34, pp.115-47. 
Allan, S. and Thorsen, E. (Eds) (2009), Citizen Journalism: Global Perspectives, New York, Peter Lang.

Beegan, G. and Atkinson, P. (2008), "Professionalism, amateurism and the boundaries of design”, Journal of Design History, Vol. 21, No. 4, pp.305-13.

Boltwood, P. (2000), “An amateur astronomer's experiences with amateur-professional relations", in Percy, J and and Wilson, J (Eds), ASP Conference Series, Vol. 120, pp.188-95. Bourgeault, I.L., Benoit, C. and Hirschkorn, K. (2009), “Comparative perspectives on professional groups: Issues and critical debates”, Current Sociology, Vol. 57, p.475. Bovaird, T. (2007), "Beyond engagement and participation: User and community coproduction of public services”, Public Administration Review, Vol. 67, pp.846-860. Cain, J. and Romanelli, F. (2009), "E-professionalism: A new paradigm for a digital age", Currents in Pharmacy Teaching and Learning, Vol. 2, No. 1, pp.66-70.

Clark, C. (2005), “The deprofessionalisation thesis, accountability and professional character", Social Work and Society, Vol. 3, No. 2, http://www.socwork.net/sws/article/view/193/480

Collins, H. and Evans, R. (2007), Rethinking Expertise, Chicago, University of Chicago Press.

Czarniawska, B. (2011), Cyberfactories: How News Agencies Produce News, Cheltenham, Edward Elgar.

Dodge, M. and Kitchen, R. (2013), "Crowdsourced cartography: Mapping experience and learning", Environment and Planning A, Vol. 45, No. 1, pp.19-36.

Edwards, A., Daniels, H., Gallagher, T., Leadbetter, J. and Warmington, P. (2009), Improving Inter-professional Collaborations: Multi-agency Working for Children's Wellbeing, London, Routledge. 
Ellis Paine, A., Hill, M. and Rochester, C. (2010), 'A rose by any other name...' Revisiting the 'what exactly is volunteering' question, London, NCVO.

Estellés Arolas, E. and González Ladrón-de-Guevara, F. (2012), “Towards an integrated crowdsourcing definition”, Journal of Information Science, Vol. 31, No. 2, pp.189-200. Evetts, J. (2009), "New professionalism and new public management: Changes, continuities and consequences", Comparative Sociology, Vol. 8, No. 3, pp.247-266.

Evetts, J (2011), “Sociological analysis of professionalism: Past, present and future”, Comparative Sociology, Vol. 10, No. 1, pp.1-37.

Fenwick, T. (2012a), “Complexity science and interprofessional learning for collaboration: A critical reconsideration of possibilities and limitations", Journal of Education and Work, Vol. 25, No. 1, pp.141-162

Fenwick, T. (2012b), "Co-production in professional practice: A sociomaterial perspective", Professions \& Professionalism, Vol. 2, No. 2, pp.1-16.

Fenwick, T. (2013), “Understanding transitions in professional practice and learning: Towards new questions for research", Journal of Workplace Learning, Vol. 25, No. 6, pp.352-367.

Friedson, E. (1988), Professional Powers: A Study of the Institutionalisation of Formal Knowledge, Chicago, University of Chicago Press.

Friedson, E. (2001), Professionalism: The Third Logic, Cambridge, Polity Press.

Greysen S, Kind T. and Chretien K. (2010), "Online professionalism and the mirror of social media", Journal of General Internal Medicine, Vol. 25, No. 1, pp.227-9. Johnson, T. (1972), Professions and Power, London, Macmillan. Keen, A. (2007), The Cult of the Amateur, New York, Doubleday/Currency. 
Klette, K. and Smeby, J-C. (2012), "Professional training and knowledge sources", in Jensen, K., Lahn, L. and Nerland, M. (Eds), Professional Learning and the Knowledge Society, Rotterdam, Sense Publications.

Lankford, J. (1981), “Amateurs versus professionals: The controversy over telescope size in late Victorian Science”, Isis, Vol. 72, No. 1, pp.11-28.

Leadbeater, C. and Miller, P. (2004), The Pro-am Revolution: How Enthusiasts Are Changing Our Economy and Society, London, DEMOS.

Mansfield, S.J., Morrison, S.J., Stephens, H.O., et al. (2011), "Social media and the medical profession”, Medical Journal, Vol. 194, No. 12, pp.642-654.

Meyer, M. (2008), "On the boundaries and partial connections between amateurs and professionals", Museum and Society, Vol. 6, No. 1, pp.38-53.

Novotny, K. (2000), "Experts in their own lives: Emphasising client-centeredness in a homeless program”, Policy Studies Journal, Vol. 28, No. 2, pp.382-401.

Nowotny, H., Scott, P. and Gibbons, M. (2001), Rethinking Science, Cambridge, Polity Press. Oxford Economics (2008), The Public Service Industry in the UK, Oxford: Oxford Economics.

Perry, J., Brudney, J., Corsey, D. and Littlepage, L. (2008), “What drives morally committed citizens? A study of the antecedents of public service motivation", Public Administration Review, May/June, pp.445-458.

Raddick, M. Jordan, Bracey, G., Gay, P., Lintott, C., Cardamone, C., Murray, P., Schawinski, K., Szalay, A. and Vandenberg, J. (2013), "Galaxy zoo: Motivations of citizen scientists", Astronomy Education Review, Vol. 12, No. 1, 010106, http://dx.doi.org/10.3847/AER2011021. Roy, H.E., Pocock, M.J.O., Preston, C.D., Roy, D.B., Savage, J., Tweddle, J.C. and Robinson, L.D. (2012) Understanding Citizen Science \& Environmental Monitoring, Final 
Report on behalf of UK-EOF, NERC Centre for Ecology \& Hydrology and Natural History Museum.

Seddon, T. (1997), "Education: deprofessionalised? Or regulated, reorganised and reauthorised?", Australian Journal of Education, Vol. 41, No. 3, pp.228-46.

Star, S. and Griesemer, J. (1989), “Institutional ecology, 'translations' and boundary objects: Amateurs and professional in Berkeley's museum of vertebrate zoology, 1907-39”, Social Studies of Science, Vol. 19, No. 3, pp.387-420.

Stebbins, R. (1992), Amateurs, Professionals and Serious Leisure, Montreal, McGill-Queens University Press.

Waring, M. (1988), If Women Counted: A New Feminist Economics, London, Harper and Row.

Week, W. (1988), “De-professionalisation or a new approach to professionalism?”, Australian Social Work, Vol. 41, No. 1, pp.29-37. 